Journal of Computer Science 4 (10): 807-814, 2008

ISSN 1549-3636

(C) 2008 Science Publications

\title{
Prayer Times Modeling with GIS: A Case Study for Iran and Its Surrounding
}

\author{
${ }^{1}$ Hossein Aghighi, ${ }^{2}$ Abbas Alimohammadi and ${ }^{3}$ Mohammad Sadeghi Ghahareh \\ ${ }^{1}$ Iranian Space Agency, Space Research Center, No 80, \\ 14th Street, Saadat Abad Avenue, Postal Code: 1997994313 Tehran, Iran \\ ${ }^{2}$ Departmebt of GIS, Faculty of Geomatics, Khaje Nasir Toosi University of Technology, \\ Valiasr avenue, Afront of Eskan building, Tehran, Iran \\ ${ }^{3}$ Department of Remote Sensing and GIS, Iranian Space Agency, \\ No 57.2, Sayeh Ave., Jordan Str., Tehran, Iran
}

\begin{abstract}
Traditionally, the time of prayer was being announced through mosques. Nowadays, there's a special time in cities of Muslim countries, known as prayer times table. Mean while villages lack such division or table, they use the Prayer times of nearby cities. In non-muslim countries, such tables just belong to big cities and other areas have difficulties to find (precise) prayer times. Quantitative computation of Prayer times is dependent on geographical coordinate of that place and space/time position of Sun. Residential areas were determined as polygon and each of them are located in a specific geographical coordinate. It's not possible to use the Prayer time of one point for another point far from that. In this research, the area was divided into pixels of $1000 * 1000 \mathrm{~m}$ and Prayer time was calculated with astronomical relations. The accuracy of this study had been compared to those were presented by calendar center of geophysics institute (University of Tehran) and had perfect accuracy. Prayer time was calculated for each pixel of the studying area by GIS. Results of this research showed the necessity of GIS in determining Prayer times and led to more accuracy of calculations.
\end{abstract}

Key words: Daily prayers times, modeling, GIS

\section{INTRODUCTION}

To Muslims, Prayer is the best act to worshiping Allah. If it is accepted by the Almighty, other acts of worshipping will also be accepted and if it is not accepted, other acts won't be accepted. Hence daily Prayers are considered as an important part of a Muslim's life. In several parts of holly Qur'an these times are directly or indirectly addressed.

Establish Prayer at the setting of the Sun until the dark of the night (Zuhr, Asr, Maghrib and Isha Prayers) and the recital of Qur' an at dawn (Fajr) Prayer. Lo! The recital of the Qur'an at dawn is ever witnessed (ALISRA, 17:78).

Traditionally, in Muslim countries, the time of Athan has been announced through mosques but the Muslim in non-Islamic countries don't have this fortune. Nowadays in different cities, there are time tables, which show the Prayer time. In some Muslim countries and in most non-Muslims countries, the above-mentioned tables are just for big and major cities and villages in Muslim countries and small cities and villages in non-Muslims countries don't have that's. Generally, these tables don't have enough accuracy for all Muslims living in those countries (As mentioned, Prayer time studying is so important). Prayer times are defined in Islamic references and can be computed by astronomical equations, so that source could be divided in two parts as well: Islamic reference, astronomical references.

Islamic reference: The Prayer times are defined as ${ }^{[1]}$

Time of Zuhr-midday and Asr-afternoon-Prayers: If a stick or anything like it is made to stand on a level ground, when the Sun rises its shadow will fall west wards and as the sun continues to rise, the shadow cast by the indicator will reduce in size. In cities of our country at the beginning of Zuhr-midday- it is in its shortest size and as midday passes, thy shadow gets longer. Based on this, when the shadow is the shortest in size and it begins getting longer again, it is known as Zuhr-midday-has taken place.

Corresponding Author: Hossein Aghighi, Iranian Space Agency (ISA), Space Research Center, No 80, 14th Street, Saadat Abad Avenue, Postal Code: 1997994313 Tehran, Iran 


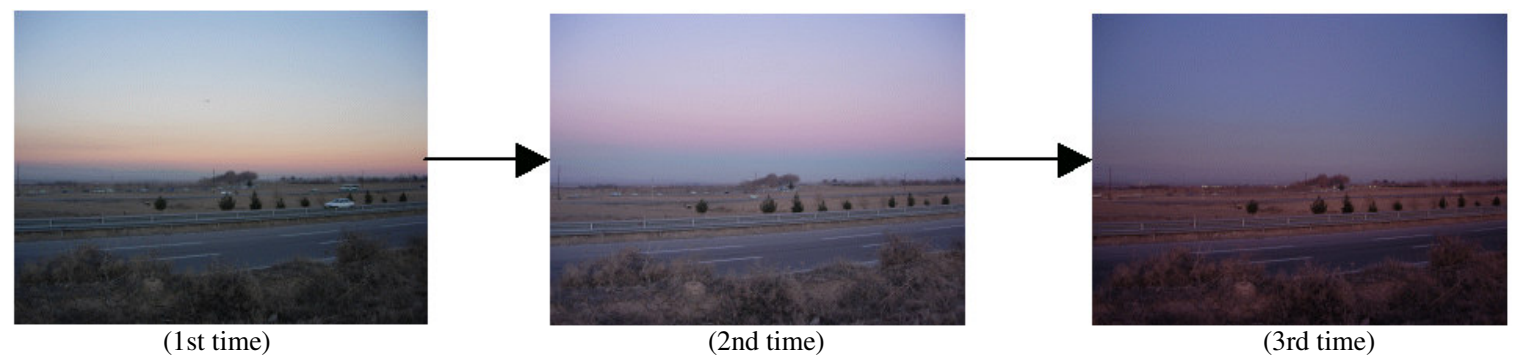

Fig. 1: Photos show the changes in thy sky redness in east ward vanishes gradually and is known as time of Maghrib-dusk-Prayer these photos have been taken in coordinate of (59: 40: 49, 36, 10, 58) in Jan/26/2007, at the time of Maghrib Prayer

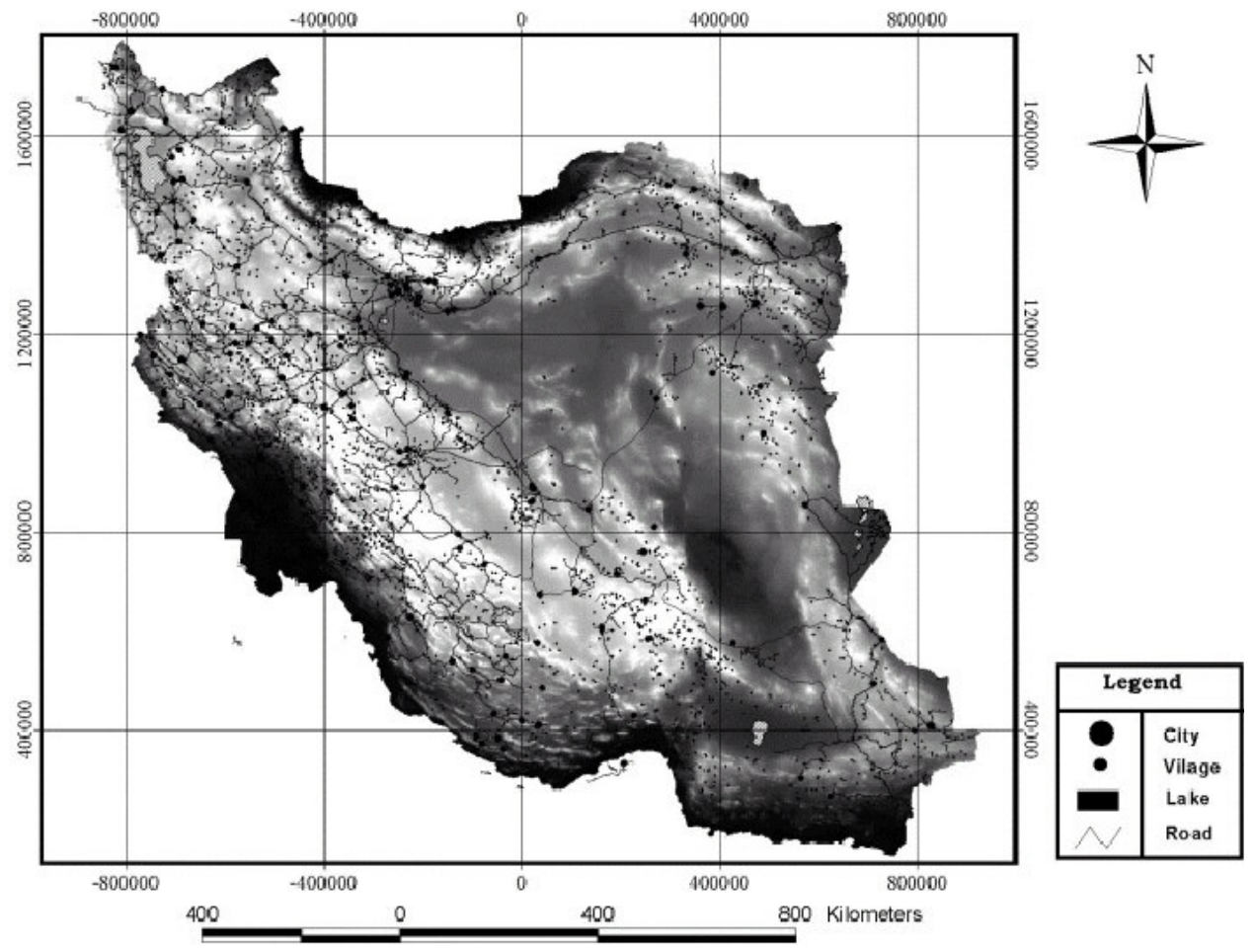

Fig. 2: The distribution of villages and cities of Iran

Time of Maghrib-dusk-and Isha-night-Prayers: Time of Maghrib-Dusk-and Isha-night-Prayers: Maghrib is thy time that the redness in the eastern sky appears after sunset has passed over head (Fig. 1).

Time of Fajr-dawn-Prayers: just before dawn, a column of whiteness rises upwards from the east, it is called the first dawn, when this whiteness spreads, it is called the second dawn and the prime time for Dawn Prayers. The final time for Dawn Prayers is when the sun rises. There are two dawns: The first is called false dawn (al-Fajr.al-kazib) for, it vanishes in a short time. It is also called the tail of the wolf. Because it look as if a tail is raised. This false dawn is a beam of light like a vertical column; it appears at the end of the night on the eastern horizon when the sun reaches an angle of $18^{\circ}$ below the horizon. Then it gives way to a horizontal line of light which looks as if a white thread has been stretched on the horizon. This is the second dawn. It is called true dawn (al-Fajr as-sadiq) for, it truthfully announces the arrival of day-time and is connected with sunrise.

As it is obvious in above-mentioned subjects, the time of Prayer for each point is based on astronomical events and these events are dependent on astronomical position of sun in its daily movement. 
Astronomical references although scientific references of solar literature contain comprehensive studies on computing the position of sun, they can be divided into two general categories: First category consists of references and articles dealing with basic formulas and algorithms. Such as, day of the year, Julian days, basic parameters on computing the position of sun and calculations like, solar declination, hour angle, equation of time ${ }^{[2-8]}$. The second category consists of references dealing with complex algorithms such as: Precise location and instant of observation, compute the position of the Sun in ecliptic (ecliptic longitude, obliquity), celestial (declination, right ascension), local horizontal coordinates (zenith distance and solar azimuth) and solar radiation ${ }^{[9-19]}$.

The basic equations on computing the position of sun can be found in most solar reference books and paper $^{[2,4-11,17,19-22]}$.

As it is obvious in above-mentioned subjects, the time of Prayer for each point is based on astronomical events and these events are dependent on astronomical position of sun in its daily movement. The important thing is that the mentioned times are dependant on geographical position and proportional position of the day within the year. Hence, it's not possible to apply the Prayer timetable of one city for villages or other residential areas rather than that city. On the other hand in a country like Iran which is located in dry and semidry regions and its villages are spread out in a wide area, this problem seems to be really important (Fig. 2).

To solve the problem of Prayer time GIS could be applied. Mostly, one of the major goals of GIS is its predicting potential. Prediction based on GIS consists of using map geometry to find symbolic models, which requires layer combination ${ }^{[30]}$. Hence, the goal of this study is to estimate the outcome of GIS in Prayer time computing and raster maps with perfect accuracy in which the value of pixels show the exact Prayer time.

\section{MATERIALS AND METHODS}

Studying area: Studying area is an area in coordinate of $(39.329 \mathrm{E}, 18.869 \mathrm{~N})-(69.592 \mathrm{E}, 42.822 \mathrm{~N})$. In center of this area Iran is located with-28 meters of Caspian level as minimum and Damavand with $5670 \mathrm{~m}$ as maximum elevation ${ }^{[24]}$. The studying area contains: Iran, Caspian Sea and some part of Indian Ocean, Black sea and 19 countries around Iran (Fig. 3). The elevation changes of Iran can be observed through the DEM within map 2 background which shows enormous elevation changes in Iran.

The formulas to determine Prayer time: To calculate the Prayer times for each point, we need to have the spatial (Longitude, latitude, elevation of the point and reference longitude), temporal (Day number) and astronomical data (Declination angle of the sun, Equation of time and Twilight angle).

Solar declination $(\delta)$ shows the earth's angular tilt to the sun, which shifts seasonally $\pm 23^{\circ} 27^{\prime}$ between vernal and autumnal equinoxes ${ }^{[11]}$. The declination can be approximated from the following equation ${ }^{[2,4,25]}$ :

$$
\delta(n)=23.45^{*} \sin \left(2 \pi \frac{284+n}{365}\right)
$$

$\mathrm{n}=$ Daynumber, January $1=$ day 1

The equation of time (EOT) account for the earthsun geometric relationship and is calculated as Eq. $2^{[28-29,32-33]}$ :

$$
\begin{aligned}
\mathrm{EOT}= & -7.64 \operatorname{Sin}(360 \mathrm{n} / 365.24) \\
& +9.65 \operatorname{Sin}\left(\frac{(\mathrm{n}-78)^{*} 180}{92}\right)
\end{aligned}
$$

$\mathrm{n}=$ Daynumber, January $1=$ day 1

Local Noon Time (LNT) the noon is called local because the time at which it occurs depends on location of the observer. At local noon time the Sun's altitude is the largest for that day. Local noon is the time of day when the shadow of a vertical gnomon is shortest ${ }^{[28]}$.

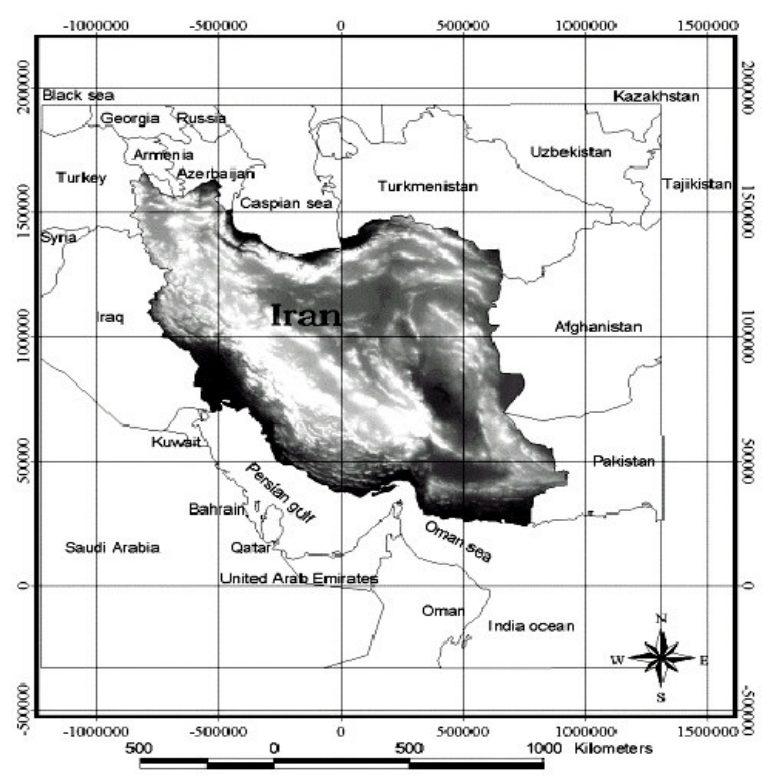

Fig. 3: The map of studying area 
With respect to definitions, noon-time Prayer is the same as local noon time.

The transit time of a celestial body refers to the instant that its center crosses an imaginary line in the sky-the observer's meridian-running from north to south $^{[13]}$.

LAT is the local apparent time or true solar time. The local apparent time can be related to the Local Mean Time (LMT) ${ }^{[27]}$ :

$$
\mathrm{LAT}=\mathrm{LMT}+\mathrm{EOT}-\left(\frac{\Delta \mathrm{l}}{15}\right)
$$

where, LAT is Local apparent time (Zuhr time), EOT is Equation of time (h) and $\Delta \mathrm{l}$ is Correction due to reference longitude

For local noon time, LMT is 12 in universe time $^{[28-30]}$.

So:

$$
\mathrm{LNT}=12-\left(\frac{\mathrm{EOT}}{60}\right)-\left(\frac{\Delta \mathrm{l}}{15}\right)
$$

Time of sunrise and sunset: Rise and set are defined as the moments when the upper limb of a body is on the visible horizon ${ }^{[13,29,31,32]}$. The time of rise and set is related to refraction, horizontal parallax, DIP and semi diameter. These quantities determine the altitude (Ho) of a body with respect to the celestial horizon at the instant of the visible rise or set ${ }^{[19]}$ :

$$
\begin{gathered}
\mathrm{S}=\arccos \left(\frac{\sin \text { Ho }-\sin \text { Lat.Sin } \delta}{\cos \text { Lat.cos } \delta}\right) \\
\text { Ho }=\text { HP-SD-R } \mathrm{R}_{\mathrm{H}} \text {-Dip }
\end{gathered}
$$

According to the Nautical Almanac, the refraction for a body being on the sensible horizon, $\mathrm{RH}$ is approximately 34 .

In this formula: HP is Horizontal parallax:

$$
\mathrm{HP}=\arcsin \left(\frac{\mathrm{r}_{\mathrm{E}}[\text { км }]}{\text { distance }[\text { км }]}\right) \approx 0.15^{\prime}
$$

where, $r_{E}$ is the equatorial radius of the earth $(6378 \mathrm{~km})$ and SD is Semi diameter of a Sun:

$$
\mathrm{SD}=\arcsin \left(\frac{\mathrm{r}_{\mathrm{B}}[\text { км }]}{\text { distance }[\text { км }]}\right) \approx 16^{\prime}
$$

where, $r_{B}$ is the Radius of the Sun (696260 KM) and Dip is dip of horizon.
The altitude of the sensible horizon related to the visible horizon is called dip and is a function of the height of eye:

$$
\operatorname{Dip}[] \approx 1.76 \cdot \sqrt{\mathrm{HE}[\mathrm{m}]} \approx 0.97 \cdot \sqrt{\mathrm{HE}[\mathrm{ft}]}
$$

HE: The vertical distance of the observer's eye from the earth's surface

The above formula is empirical and includes the effect of the curvature of the earth's surface and atmospheric refraction. When observing the upper limb of the sun, we get:

$$
\mathrm{HO}=15^{\prime}-16^{\prime}-34^{\prime}-\mathrm{Dip} \approx-50^{\prime}-\mathrm{Dip}
$$

So:

$$
\begin{gathered}
\mathrm{S}=\arccos \left(\frac{\sin \left(-50^{\prime}-1.76 \sqrt{\mathrm{HE}[\mathrm{m}]}\right)-\sin \text { Lat.Sin } \delta}{\cos \text { Lat.cos } \delta}\right) \\
\text { Sunrise }=\text { LNT }-\left(\frac{\mathrm{t}}{15}\right) \\
\text { Sunset }=\text { LNT }+\left(\frac{\mathrm{t}}{15}\right)
\end{gathered}
$$

Local Fajr time and local Maghrib time: An object below the horizon would not be visible, but it may be considered as having a negative altitude. An example of this is the Sun and twilight ${ }^{[12]}$. Before sunrise and again after sunset there are intervals of time, twilight, during which there is natural light provided by the upper atmosphere, which does receive direct sunlight and reflects part of it toward the Earth's surface ${ }^{[13]}$. Morning twilight ends at sunrise and evening twilight begins at sunset $^{[33]}$. The altitudes of the center of Sun used for twilight is $-6,-12,-18$ for civil, nautical, astronomical twilight ${ }^{[13]}$.

Considering these explanation, if refer to definition of Time of Fajr it is found out that the time of morningSobh Athan-and the final time for morning Prayer can be computed by twilight and sunrise. Therefore:

$$
\mathrm{t}=\arccos \left(\frac{-\sin \mathrm{tw}-\sin \text { lat.sin Dec }}{\text { coslat.cos Dec }}\right)
$$

Tw: Twilight angle ${ }^{[18]}$

$$
\mathrm{Lft}=\mathrm{Lnt}-\frac{1}{15} \mathrm{t}
$$


So, to compute Fajr time, twilight is considered as to be 17.7:

$$
\mathrm{Lmt}=\mathrm{Lnt}+\frac{1}{15} \mathrm{t}
$$

To compute Maghrib time, twilight is considered as 4.5. There, Lft is Local Fajr time, Lnt is Local noon time and Lmt is Local Maghrib time.

With respect to above elaborations by principal clergy men, the prime time for Morning Prayer is Lft and the final time is sunrise.

Applied materials: The mentioned function (Eq. 1-16) obviously depicts the necessity of data like; latitude, longitude, elevation and the day of the year as basis data.

GIS plays a key and important role in preparing Prayer time map. Since the goal of this research is to prepare maps for Prayer time for each point, the raster models have been used for map algebra and preparation the continuous Prayer time map. The information used in this research is as follow: DEM with pixel size of 1000 meters which has been obtained through resampling the DEM of $1 / 250000$ with pixel size of $100 \mathrm{~m}$. During next step, two raster files have been produced through the DEM with pixel size of $1000 \mathrm{~m}$, in one of them, the DN of each pixel represents the longitude of that pixels center and in next file, the DN represents latitude. With such files, the position of each point in the studying area has been continuously modeled in 3dimensions: longitude, latitude, elevation. The mentioned data were space data in Lambert conformal conic coordinate system. The temporal data is the day of the year. Hence, a table has been prepared, started from 1st of January to the end of the year (numbering as 1 st of January $=1$ ).

Methodology: A GIS database was formed which consists of space/time data. The database contains information in 4 dimensions: 2 of them represent space positions, third is elevation and fourth, Time. Day of year is known as the producing source of daily information on Declination angle, Equation of time and distance between earth and sun. The information has been obtaiend in Eq. 1 and 2). In next phase, the equations Eq. 3-16 had solved operationally; the steps were designed in GIS. The result was the raster files in which DN pixels of each layer shows the amount of Prayer time for that time and day. The procedures are presented in Fig. 4.

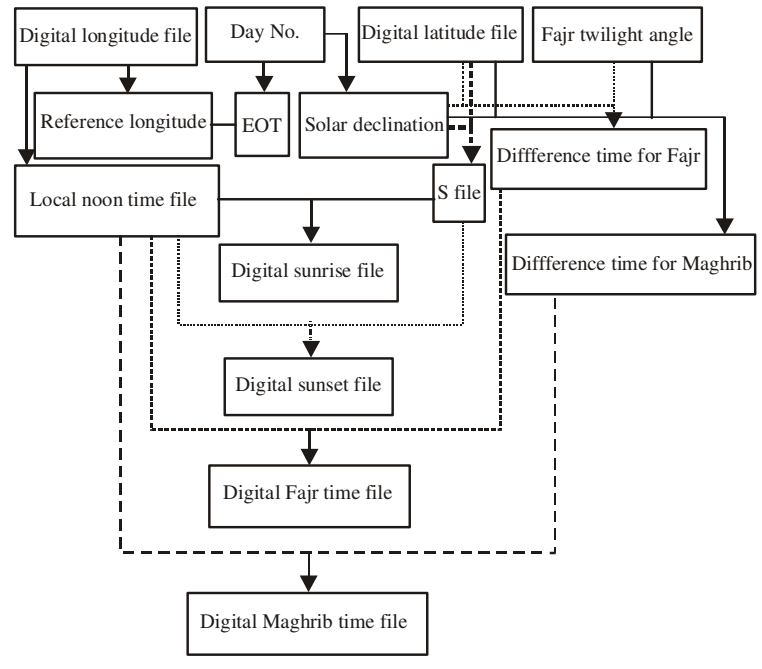

Fig. 4: Computing stages and Prayer time map preparation

The maps prepared with such procedure have been compared with those of Calendar Center of Geophysics Institute (University of Tehran). The comparisons have been done for 5 cities of Iran: Tehran $(51.4 \mathrm{E}, 35.7 \mathrm{~N})$, Mashhad (59.58E, 36.31N), Bandar Abbas (56.29E, $27.19 \mathrm{~N})$, Kerman shah (47.09E, 34.34N) and Sari $(53.06 \mathrm{E}, 36.75 \mathrm{~N})$. These points are widely spread all over Iran so that it's tried to select them among: east, west, north and south of Iran. To examine accuracy, 40 different days of the year have been selected Randomly-systematically. In the selected dates, the information of maps has been compared with those of Geophysics Institute.

\section{RESULTS}

By developing the algorithms of above equations, the Prayer time has been computed for the studying area. The produced data are those of raster in which DN of each pixel represents the Prayer time and then in order to prepare the map, simultaneous contours have been extracted through data. As an instance, the map in Fig. 5 shows the contours of Fajr Prayer time in 16th/Dec/2006. With respect to high density of contours in studying area, the map of Tehran province is represented individually

The refraction in Eq. 6 is dependent on atmosphere temperature and pressure ${ }^{[29]}$, in this study the elevation of the area is equal to elevation of sea level which is zero. As it is obvious in the above map, Fajr Prayer time is computed for each point of the studying area, the contour lines are extracted with minute interval. 


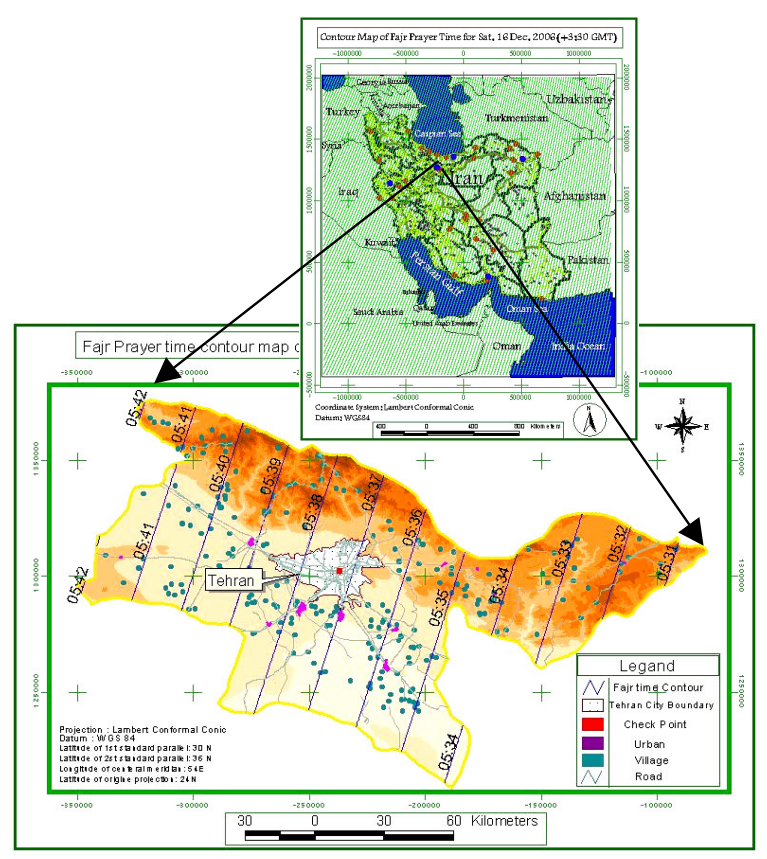

Fig. 5: The map of simultaneous contours, for Fajr Prayer in the studying area and Tehran province

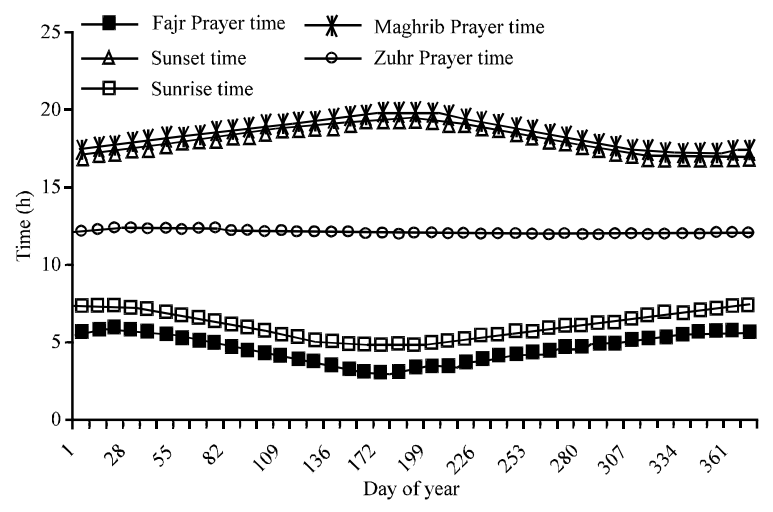

Fig. 6: Time changes of Fajr Athan, sunrise, noon time Athan, sunset, Maghrib Athan-Athan during 20052006 in Tehran

Figure 6 show local Prayer time changes (51/41 E, $35 / 7 \mathrm{~N}$ ) in Tehran, 2005-2006. As it is obvious the Prayer time of Fajr with sunrise and Maghrib with Sunset has similar changes trend. With respect to calculations for mentioned points:

\section{Sunrise-Fajr $>$ Maghrib-Sunset}

This phenomenon can be observed in other graphs and in graphs dealing with Fajr and sunset, the distance is more.
Table 1: Comparison of data gained through this method to those of geophysics institute

\begin{tabular}{|c|c|c|c|c|c|}
\hline No. & City name & Longitude & Latitude & $\begin{array}{l}\text { Fajr } \\
\text { prayer } \\
\text { time (Map) }\end{array}$ & $\begin{array}{l}\text { Fajr prayer } \\
\text { time (Institute } \\
\text { of Geophysics) }\end{array}$ \\
\hline 1 & Tehran & 51.41 & 35.70 & $37: 15.6$ & $5: 37$ \\
\hline 2 & Mashhad & 59.58 & 36.31 & 5: $05: 24$ & 5: 05 \\
\hline 3 & Bandar Abas & 56.29 & 27.19 & $05: 34.8$ & 5: 06 \\
\hline 4 & Kerman Shah & 47.09 & 34.34 & $52: 33.6$ & 5: 53 \\
\hline 5 & Sari & 53.06 & 36.57 & $31: 55.2$ & $5: 32$ \\
\hline
\end{tabular}

This phenomenon is due to difference in degrees of twilight angle, for the time different of sunrise and sunset is equal from midday, but the degree of twilight angle for Fajr time is more in comparison to Maghrib. Hence, the computed times are different and it leads to the above mentioned situations.

This issue clarifies the importance of careful calculation of twilight angle. Regarding to relation number 14, the less the twilight angle, the Fajr time and sooner Maghrib will be.

Table 1 shows the data in comparison to those of Geophysics Institute in 16. Dec.2006

As it is obvious, in Table 1, the accuracy of data presented by Calendar Center of Geophysics Institute (University of Tehran)-as an official authority to determine Prayer times in Iran- is into minute. Whereas if the data of this report-which tends to determine accuracy- turn into minute, the curve of this comparison would be $R^{2}=1$ and the equation $\mathrm{Y}=\mathrm{X}$. This matter is also correct for control data, so it's avoided to present the graphs due to repetition.

This methode is important for villages and migrating tribes and Muslims of countries in which there's no Prayer time.

\section{CONCLUSION}

The noticeable point is related to Prayer time calculation center for Muslims in which they use relations to compute Prayer times of cities. The Muslims of every country use a spatial point related to that region to announce the Prayer time of residential areas, but all residential areas are as polygons. In such cases, the key questions are: which point of polygone of city should be taken as index point? East, center or west of the city and whether the point of one city can be applied for small cities or villages near by?

If so, 3 major questions are posed related to holly month of Ramadan:

- The time of Maghrib Prayer is calculated for eastern part of the city, consequently the people living on center and west of city break the fast, mean while, yet it's not the time of Athan for them 
- The time of Sobh-Dawn-Prayer is calculated for western part of city, at this time, the people in center or east of city still having breakfast-Saharimean while the time of Dawn Athan is up

- The time of Athan is calculated for center of the city. If so, the two mentioned problems will come true

The 3 cases clarified above will cause doubt in people's fasting. But how can these problems be solved?

- The scientific method is applying GIS in computing Prayer time

- The second method is to determine dawn Athan according to coordinate of eastern part in the city and the other Prayer times according to western parts of the city

It seems as if this suggestion can solve the problem for one city but it can't come true for villages which use the Prayer time of that city, therefore, the best way is to apply GIS in computing Prayer times precisely as described previously, theoretically the elevation can effect on accurate calculation of Prayer times.

So, if careful field studies confirm it, the importance of GIS even seems more efficient and effective since elevation is a variable and continuous parameter, it can't be applied in Prayer times calculations.

Therefore, in such cases using the DEM of the region in GIS-based Prayer times is of a great importance.

Considering these issues, applying GIS in computing Prayer time is clear and evident and it is suggested the scientific authorities of Muslim and nonMuslim countries- who are responsible for such calculations-apply GIS in computing Prayer times.

\section{ACKNOWLEDGMENT}

It is worthy to mention that the following organizations and staffs are appreciated warmly due to their sincere Cooperation: Iranian Space Agency for its basic data, Calendar Center of Geophysics Institute (University of Tehran) for Prayer times table available on its site.

\section{REFERENCES}

1. Fazel Lankarani, M., 2004. Islamic Laws, English Version of Tawdih-al-Masael. Amir-Al-Elm, Iran, pp: 144-148.
2. Cooper, P.I., 1969. The absorption of radiation in solar stills. Solar Energ., 12: 333-346. DOI: 10.1016/0038-092X(69)90047-4

3. Sayigh, A.A.M., 1977. Solar Energy Engineering. Academic Press, New York, ISBN: 0126208506.

4. Duffie, J.A. and W.A. Beckman, 1991. Solar Engineering of Thermal Processes. Wiley Interscience, New York, ISBN: 0471510564, pp: 944.

5. Lamm, L.O., 1981. A new analytic expression for the equation of time. Solar Energ., 26: 465. DOI: 10.1016/0038-092X(81)90229-2

6. Kreider, J.F. and F. Kreith, 1981. Solar Energy Handbook. McGraw-Hill, New York, ISBN: 007035474X, pp: 1100.

7. Wieder, S., 1982. An Introduction to Solar Energy for Scientists and Engineers. John Wiley, New York, ISBN: 0471060488.

8. Muir, L.R., 1983. Comments on the effect of atmospheric refraction on the solar azimuth. Solar Energ., 30: 295 . DOI: 10.1016/0038092X(83)90164-0

9. Michalsky, J.J., 1988. The astronomical almanac's algorithm for approximate solar position (19502050). Solar Energ., 40: 227-235. DOI: 10.1016/0038-092X(88)90045-X

10. Pitman, C.L. and L.L. Vant-Hull, 1978. Errors in locating the Sun and their effect on solar intensity predictions. Proceeding of the Meeting on American Section of the International Solar Energy Society, Aug. 28-28, Denver, pp: 205-206.

11. Walraven, R., 1978. Calculating the position of the Sun. Solar Energ., 20: 393-397. DOI: 10.1016/0038-092X(78)90155-X

12. Birney, D.S., G. Gonzalez and D. Oesper, 2006. Observational Astronomy. 2nd Edn., Cambridge University Press, Cambridge, ISBN: 13: 9780521853705, pp: 322.

13. Seidelmann, P.K., 2005. Explanatory Supplement to the Astronomical Almanac. Revised Edn., University Science Books, ISBN: 13: 9781891389450, pp: 752.

14. EI Diasty, R., 1998. Variable positioning of the sun using time duration. Renew. Energ., 14: 185-191. DOI: 10.1016/S0960-1481(98)00066-4

15. Quasching, V. and R. Hanithsch, 1998. Irradiance calculation on shaded surfaces. Solar Energ., 62: $\quad 369-375$. DOI: $10.1016 /$ S0038092X(98)00018-8

16. Blanco-Muriel, M., C. Alarcon-Padilla, T. LopezMoratalla and M. Lara-Coira, 2001. Computing the solar vector, Solar Energ., 70: 431-441. DOI: 10.1016/S0038-092X(00)00156-0 
17. Vijayakumar, G. et al., 2005. Analysis of shortterm solar radiation data. Solar Energ., 79: 495-504. DOI: 10.1016/j.solener.2004.12.005

18. Elminir, K.H. et al., 2005. Estimation of solar radiation components incident of Helwan site using neural networks. Solar Energ., 79: 270-279. DOI: 10.1016/j.solener.2004.11.006

19. Umland, H., 2006. A short guide to celestial navigation. (Ebook: http://www.celnav.de.)

20. Iqbal, M., 1984. An Introduction to Solar Radiation. Academic Press Inc., New York, ISBN: 13: 978-0123737502, pp: 390.

21. Spencer, J.W., 1971. Fourier series representation of the position of the Sun. Search, 2: 172. $\mathrm{ftp} / / / \mathrm{ftp} . g c s t u d i o . c o m / p u b /$ sundial/fourier.doc.

22. Swift, L.W., 1976. Algorithm for solar radiation on mountain slopes. Water Resour. Res., 12: 108-112. DOI: 10.1029/WR012i001p00108

23. Bonham-Cater, G.F., 1994. Geographic Information Systems for Geoscientists: Modeling with GIS. 1st Edn., Pergamon, ISBN: 13: 9780080418674.

24. Darvichzadeh, A., 1992. Geology of Iran. NEDA Press, Iran (Farsi).

25. Cousins, F.W., 1969. Sundials: A Simplified Approach by Means of the Equatorial Dial. John Baker Publishers, London.

26. Meeus, J., 1998. Astronomical Algorithms.2nd Edn., Willmann-Bell, ISBN-10: 0943396611, pp: 477.
27. Sattler, M.A., S. Sharples and J.K. Page, 1987. The geometry of the shading of buildings by various tree shapes. Solar Energ., 38: 187-201. DOI: 10.1016/0038-092X(87)90017-X

28. Ray, R.J., R.E. Loughhead and C. J. Durrant, 1984. The Solar Granulation. 2nd Edn., Cambridge University Press, Cambridge, England, ISBN: 13: 978-0521247146, pp: 288.

29. Duffett-Smith, P., 1992. Practical Astronomy with your Calculator. 3rd Edn., Cambridge University Press, Cambridge, England.

30. Zirin, H., 1988. Astrophysics of the Sun. Cambridge University Press, Cambridge, ISBN: 0521-316073, pp: 488.

31. Dershowitz, N. and E.M. Reingold, 1999. Calendrical Calculations: The Millennium Edition. Cambridge University Press, Cambridge, England.

32. Montenbruck, O. and T. Pfleger, 2000. Rising and Setting Times and The SUNSET Program. $\$ 3.6$ and 3.8 in Astronomy on the Personal Computer. 4th Edn. Springer-Verlag, Berlin, ISBN: 3540672214, pp: 300.

33. Bowditch, N., 2002. The American Practical Navigator: An Epitome of Navigation. Illustrated Edn., Paradise Cay Publications, ISBN: 13: 9780939837540, pp: 896. 